\title{
Bowman's capsule provides a protective niche for podocytes from cytotoxic CD8+ $T$ cells
}

\author{
Anqun Chen, ${ }^{1,2}$ Kyung Lee, ${ }^{2}$ Vivette D. D'Agati, ${ }^{3}$ Chengguo Wei, ${ }^{2}$ Jia Fu, ${ }^{2}$ Tian-Jun Guan, ${ }^{1}$ John Cijiang He, ${ }^{2,4}$ \\ Detlef Schlondorff, ${ }^{2}$ and Judith Agudo ${ }^{5}$
}

'Division of Nephrology, Zhongshan Hospital, affiliated with Xiamen University, Xiamen, Fujian Province, China. ²Department of Medicine, Icahn School of Medicine at Mount Sinai, New York, New York, USA. ${ }^{3}$ Department of Pathology, Columbia University Medical Center, New York, New York, USA. ${ }^{4}$ Renal Section, James J. Peters VA Medical Center, Bronx, New York, USA. ${ }^{5}$ nnstitute of Precision Immunology, Icahn School of Medicine at Mount Sinai, New York New York, USA.

\begin{abstract}
T cells play a key role in immune-mediated glomerulonephritis, but how cytotoxic $T$ cells interact with podocytes remains unclear. To address this, we injected EGFP-specific CD8 ${ }^{+} T$ cells from just EGFP death inducing (Jedi) mice into transgenic mice with podocyte-specific expression of EGFP. In healthy mice, Jedi T cells could not access EGFP+ podocytes. Conversely, when we induced nephrotoxic serum nephritis (NTSN) and injected Jedi T cells, EGFP+ podocyte transgenic mice showed enhanced proteinuria and higher blood urea levels. Morphometric analysis showed greater loss of EGFP+ podocytes, which was associated with severe crescentic and necrotizing glomerulonephritis. Notably, only glomeruli with disrupted Bowman's capsule displayed massive CD8 ${ }^{+} \mathrm{T}$ cell infiltrates that were in direct contact with EGFP+ ${ }^{+}$podocytes, causing their apoptosis. Thus, under control conditions with intact Bowman's capsule, podocytes are not accessible to CD8+ $\mathrm{T}$ cells. However, breaches in Bowman's capsule, as also noted in human crescentic glomerulonephritis, allow access of CD8 ${ }^{+} \mathrm{T}$ cells to the glomerular tuft and podocytes, resulting in their destruction. Through these mechanisms, a potentially reversible glomerulonephritis undergoes an augmentation process to a rapidly progressive glomerulonephritis, leading to end-stage kidney disease. Translating these mechanistic insights to human crescentic nephritis should direct future therapeutic interventions at blocking CD8+ $\mathrm{T}$ cells, especially in progressive stages of rapidly progressive glomerulonephritis.
\end{abstract}

\section{Introduction}

Crescentic glomerulonephritis (GN) is a devastating disease that results from immune-mediated damage to glomeruli, with proteinuria and loss of function, frequently progressing to end-stage kidney failure (1). The glomerular injury involves endothelial cells and podocytes, cells critical for maintaining glomerular architecture and function, including the ultrafiltration of the blood (1). Dysfunction or loss of the podocytes results in proteinuria and progressive deterioration of glomerular function (2). Thus, it is critical to elucidate whether and how immune cells can interact with podocytes and what the main immune effectors are. Several immune cell types have been described as playing an important role in the pathology of glomerular disease (3-7). Evidence for $\mathrm{CD}^{+} \mathrm{T}$ cell involvement has been provided in antibody-mediated GN and comes mostly from experimental nephrotoxic serum nephritis (NTSN). Moreover, subsequent work has shown the importance of both Th1 and Th17 CD $4^{+} \mathrm{T}$ cell responses, and studies on the function of $\mathrm{FOXP}^{+}$regulatory $\mathrm{T}$ cells during $\mathrm{GN}$ are rapidly expanding (3-5). The involvement of myeloid cells, such as neutrophils and macrophages, in experimental NTSN is also well established (6). Similar considerations apply to various forms of human GN, and especially those with crescentic, rapidly pro-

Authorship note: DS and JA are co-senior authors.

Conflict of interest: The authors have declared that no conflict of interest exists.

Submitted: October 4, 2017; Accepted: May 1, 2018.

Reference information: J Clin Invest. 2018;128(8):3413-3424.

https://doi.org/10.1172/JCI97879. gressing GN (RPGN), such as observed with antibody-mediated and immune complex (IC) GN, including postinfectious GN, lupus nephritis, and IgA nephropathy, as well as anti-glomerular basement membrane (anti-GBM) disease and anti-neutrophil cytoplasmic antibody-associated (ANCA-associated) vasculitis (3-5, 7). However, the role of $\mathrm{CD} 8^{+} \mathrm{T}$ cells in the generation and progression of GN remains controversial.

In both experimental NTSN and IC GN, as well as in biopsies from patients with crescentic RPGN of a variety of etiologies, a significant leukocytic infiltrate has been described (8-15). These infiltrates consist of macrophages as well as both $\mathrm{CD} 4^{+}$ and $\mathrm{CD} 8^{+} \mathrm{T}$ cells. $\mathrm{T}$ cells are prominently aggregated around Bowman's capsule (BC), but have also been noted in significant numbers inside Bowman's space at sites of crescent formation and breaches of $\mathrm{BC}(10,11)$. Further support for potential contributions of $\mathrm{CD}^{+} \mathrm{T}$ cells to experimental RPGN comes from interventional studies using antibody-mediated CD8 depletion $(3,16,17)$. In these studies, depletion of $\mathrm{CD} 8^{+} \mathrm{T}$ cells resulted in a substantial attenuation of the experimental GN in spite of comparable deposition of the pathogenic antibodies. Surprisingly, however, in vivo generation of $\mathrm{CD} 8^{+} \mathrm{T}$ cells against glomerularspecific antigens or direct intravenous administration of $\mathrm{CD} 8^{+}$ $\mathrm{T}$ cells specific for a model antigen expressed on podocytes did not result in either glomerular pathological or functional (albuminuria or blood urea nitrogen [BUN]) changes in the recipient transgenic mice (18). The mechanism for the generation of podocyte-specific antigen-directed $\mathrm{CD} 8^{+} \mathrm{T}$ cells was examined by a series of elegant experiments. It was shown that antigen from 

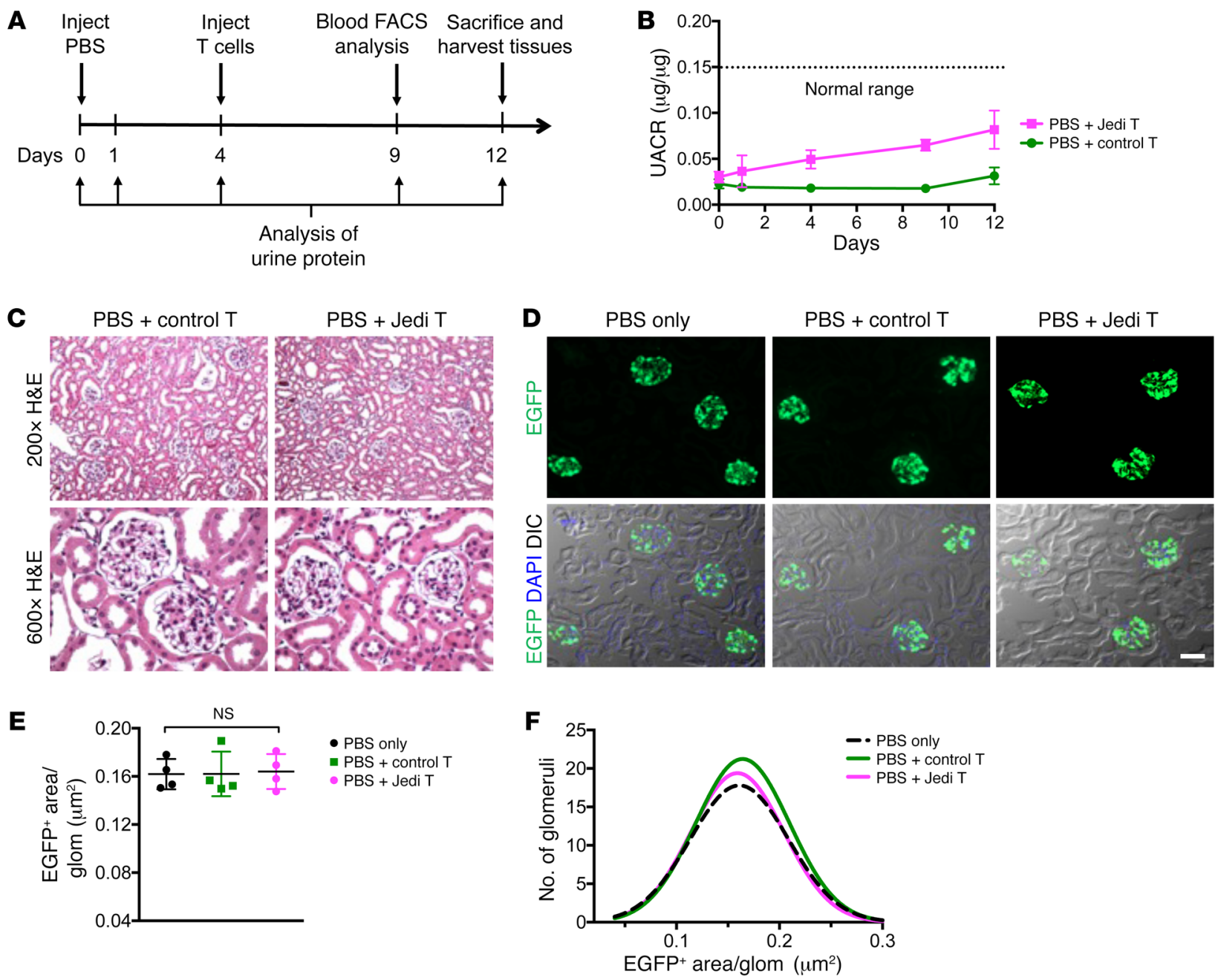

Figure 1. Effects of Jedi T cell injections on normal pod-EGFP mice. (A) Time course for the experimental protocol. Four days after intraperitoneal injection of PBS $(0.1 \mathrm{ml})$, pod-EGFP mice were coinjected with LV.EGFP and either control T cells $(n=4)$ or Jedi T cells $(n=4)$. Mice with PBS injection only served as controls $(n=4)$. (B) Urinary albumin-to-creatinine ratios (UACR, $\mu \mathrm{g} / \mu \mathrm{g})$ tested for all time points were within the normal range $(<0.15 \mu \mathrm{g} / \mu \mathrm{g})$ for both PBS plus control T cell- and PBS plus Jedi T cell-injected mice. (C) Representative H\&E-stained images of pod-EGFP kidneys. Original magnification, $\times 200$ (upper panels); ×600 (lower panels). (D) Representative images of EGFP fluorescence (top row) and merged images of EGFP, DAPI, and differential interference contrast (DIC) to identify glomeruli and tubules (bottom row). Scale bar: $50 \mu \mathrm{m}$. (E and $\mathbf{F}$ ) Quantification of the EGFP+ area in pod-EGFP mice, as $\mathrm{EGFP}^{+}$area per glomerulus (glom) (E) and size distribution curves for EGFP' area per glomerulus (F) ( $n=4$ mice, 381 glomeruli analyzed for PBS-only group; $n=4$ mice, 442 glomeruli analyzed for PBS plus control T cell group; $n=4$ mice, 420 glomeruli analyzed for PBS plus Jedi T cell groups).

podocytes was released into urine and taken up by DCs in the renal medulla. These DCs then migrated to the regional lymph nodes where, together with $\mathrm{CD} 4^{+}$helper $\mathrm{T}$ cells, they primed and activated podocyte-specific $\mathrm{CD} 8^{+} \mathrm{T}$ cells. However, in spite of the demonstration of in vitro killing of antigen-bearing podocytes by these $\mathrm{CD} 8^{+} \mathrm{T}$ cells, the authors could not demonstrate an in vivo effect of the primed $\mathrm{CD} 8^{+} \mathrm{T}$ cells on antigen-carrying podocytes. Furthermore, while $\mathrm{CD} 8^{+} \mathrm{T}$ cells isolated from mice specifically immunized against podocyte-specific antigens could enhance NTSN (18), injection of such CD8 ${ }^{+} \mathrm{T}$ cells by itself did not result in GN in healthy mice $(3,18)$. In contrast, specific expression of a model antigen on endothelial cells of glomerular capillaries was directly targeted by $\mathrm{CD} 8^{+} \mathrm{T}$ cells even in healthy mice, resulting in glomerular injury (19). However, this work again showed no evidence for development of RPGN with crescents or extravasation of T cells into Bowman's space through the injured glomeru- lar capillaries. Thus, podocytes, in contrast to endothelial cells, appear to be protected from $\mathrm{CD} 8^{+} \mathrm{T}$ cell attack.

Based on histopathological observations in experimental and human RPGN, it has been proposed that periglomerular inflammatory infiltrates and intraglomerular crescent formation may eventually facilitate access of periglomerular $\mathrm{CD} 8^{+} \mathrm{T}$ cells to Bowman's space (20). However, direct experimental evidence for this hypothesis and direct interactions of $\mathrm{CD} 8^{+} \mathrm{T}$ cells with podocytes could not be demonstrated (18). Therefore, Heymann et al. concluded that "the exact role of cytotoxic $\mathrm{CD} 8^{+} \mathrm{T}$ cells in glomerular disease is unclear, mostly because suitable animal models are lacking" (18).

In order to study in vivo $\mathrm{CD} 8^{+} \mathrm{T}$ cell interactions with a large variety of cell types, one of our groups recently developed a mouse model whose $\mathrm{CD} 8^{+} \mathrm{T}$ cells express a $\mathrm{T}$ cell receptor that specifically recognizes GFP and its more commonly used variant, EGFP, called just EGFP death inducing (Jedi) mice (21). Using multiple 
Table 1. Blood urea concentrations of mice in each experimental group (12 days after PBS or NTS injection)

\begin{tabular}{|c|c|c|c|c|c|c|}
\hline Group & PBS + control T cell & PBS + Jedi T cell & NTS only & NTS + control T cell & NTS + Jedi T cell (EGFP-) & NTS + Jedi T cell \\
\hline$n$ & 4 & 4 & 8 & 5 & 6 & 6 \\
\hline$P$ values $^{A}$ & & & $<0.05$ & $<0.01$ & $<0.01$ & $<0.0001$ \\
\hline
\end{tabular}

${ }^{A}$ Compared with PBS plus control T cell group. ${ }^{B}$ Compared with NTS plus Jedi T cell group by ANOVA with Bonferroni's modification for multiple comparison.

EGFP-expressing reporter mice, we showed that injected Jedi $\mathrm{T}$ cells can traffic to any tissue and kill diverse types of EGFPexpressing cells, such as microglia, pacemaker cells in the heart, pancreatic $\beta$ cells, and regulatory T cells (21). We took advantage of the Jedi mice in order to directly determine the accessibility of $\mathrm{CD}^{+} \mathrm{T}$ cells to podocytes in the kidney glomeruli. We generated transgenic mice with EGFP-specific expression in podocytes (22) and injected either control or Jedi T cells, so that injected Jedi T cells would behave as podocyte-specific cytotoxic T cells. Notably, we found that, under normal conditions, podocytes were protected from the injected Jedi $\mathrm{T}$ cells in transgenic mice in which only podocytes expressed EGFP (pod-EGFP mice). We hypothesized that this might be due to $\mathrm{BC}$ preventing their access to podocytes. We therefore generated crescentic NTSN with ruptures in $\mathrm{BC}$ to determine whether Jedi T cells could then migrate through defects in the capsule and gain access to $\mathrm{EGFP}^{+}$podocytes. In fact, we found this to be the case, resulting in Jedi $\mathrm{T}$ cells infiltrating the Bowman's space where the capsule was disrupted. As a consequence, glomeruli with a damaged BC displayed massive podocyte loss and a concomitant worsening of the NTSN, leading to RPGN. We observed that NTSN-mediated antigen-specific $\mathrm{CD}^{+} \mathrm{T}$ cell infiltration in the Bowman's space and podocyte loss had catastrophic consequences for glomerular and renal function, with long-lasting severe proteinuria and high blood urea levels. These findings not only provide mechanistic insight into crescentic RPGN, but are also of considerable therapeutic interest for any human form of RPGN, as treatments directed at preventing transmigration of $\mathrm{CD}^{+} \mathrm{T}$ cells into Bowman's space might prevent the progression to irreversible end-stage kidney disease even in progressive stages of crescentic GN.

\section{Results}

\section{BC prevents access of cytotoxic T cells to podocytes}

In order to determine whether podocytes could be susceptible to $\mathrm{CD}^{+} \mathrm{T}$ cell recognition, we generated pod-EGFP mice (22). Podoctye-specific EGFP expression as first confirmed by colocalization of podocin as a specific podocyte marker and EGFP in podocytes of these transgenic mice (Supplemental Figure 1A; supplemental material available online with this article; https:// doi.org/10.1172/JCI97879DS1). We also confirmed that the podocytes constitutively express MHC class I (MHC-I) $(23,24)$, which is essential for recognition by CD8 ${ }^{+} \mathrm{T}$ cells (21) (Supplemental Figure 1B). To determine whether Jedi T cells could have access and destroy $\mathrm{EGFP}^{+}$podocytes in vivo, control $\mathrm{CD}^{+} \mathrm{T}$ cells or Jedi CD8 ${ }^{+}$ $\mathrm{T}$ cells were isolated and injected in pod-EGFP mice (Figure 1A).
To ensure that Jedi T cells were fully activated, we injected EGFPexpressing recombinant lentivirus (LV.EGFP) in parallel to $\mathrm{T}$ cell adoptive transfer into both control and Jedi-treated mice, as previously reported (21). We took advantage of the existence of different haplotypes for CD45 in leukocytes of the Jedi mice (CD45.1 positive) and the $\mathrm{EGFP}^{+}$podocyte transgenic mice (CD45.2 positive) in order to detect the injected CD $45.1^{+}$Jedi T cells in the blood in the CD $45.2^{+}$recipient transgenic pod-EGFP mice (Supplemental Figure 2). Upon intravenous injection of LV.EGFP, a low percentage (1\%-3\%) of splenocytes was transduced and expressed EGFP (Supplemental Figure 2B), as previously reported (21). We confirmed the elimination of all EGFP-expressing splenocytes in Jedi $\mathrm{T}$ cell-injected mice, while mice receiving control $\mathrm{T}$ cells preserved EGFP expression in splenocytes. This indicated that Jedi $\mathrm{T}$ cells were activated and capable of killing $\mathrm{EGFP}^{+}$cells. Injection of control T cells or of Jedi T cells with LV.EGFP did not result in proteinuria (Figure 1B) or altered blood urea levels (Table 1). By light microscopy, the renal histology of control $\mathrm{T}$ cell-injected mice was totally normal (Figure 1C), and those injected with Jedi $\mathrm{T}$ cells with LV.EGFP were mostly normal, with only rare and inconsistent small periglomerular and sparse focal interstitial infiltrates (Figure 1C). The rare periglomerular and interstitial infiltrates were identified as predominantly $\mathrm{CD} 4^{+} \mathrm{T}$ cells, whereas there was no increase in $\mathrm{CD}^{+} \mathrm{T}$ cells. No glomerular infiltrates with $\mathrm{CD} 4^{+}$ or $\mathrm{CD}^{+} \mathrm{T}$ cells were seen in any group (not shown). Neither the injection of control T nor Jedi T cells altered the glomerular $\mathrm{EGFP}^{+}$ areas (Figure 1, D-F), which were used for direct measurements of podocyte cell number in pod-EGFP mice, as previously described (22). Thus, $\mathrm{EGFP}^{+}$podocytes could not be attacked by Jedi T cells even after the activation and expansion by LV.EGFP coinjection, which is in marked contrast to the complete elimination of $\mathrm{EGFP}^{+}$ splenocytes (Supplemental Figure 2B) verified in every experiment. As $\mathrm{EGFP}^{+}$podocytes were $\mathrm{MHC}-\mathrm{I}^{+}$(Supplemental Figure 1B), this could not be explained by lack of MHC-I expression.

\section{Disruption of BC in NTSN renders podocytes susceptible to $C D 8^{+} \mathrm{T}$ cell infiltration and destruction}

To evaluate whether $\mathrm{CD} 8^{+} \mathrm{T}$ cells are able to access and damage podocytes during experimental NTSN and thereby contribute to the pathology, we first induced NTSN in pod-EGFP mice and injected either control or Jedi T cells (Figure 2A). We used a mild, self-limited form of NTSN with low-dose nephrotoxic serum (NTS) without preimmunization of the mice (25). NTS was injected 4 days before the injection of T cells together with LV.EGFP.

Proteinuria and blood urea levels. After NTS injection, all groups showed rapid development of significant and comparable 
A

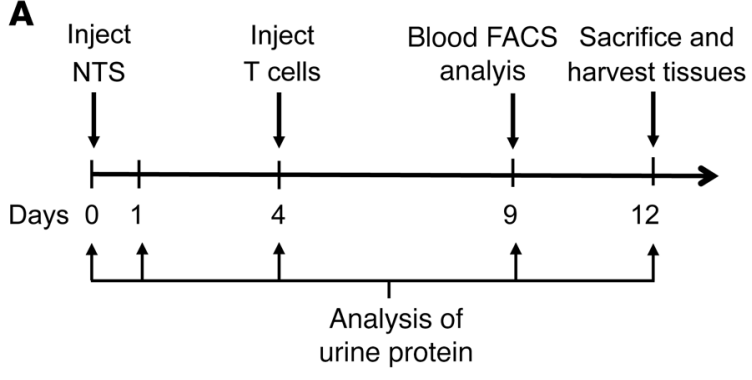

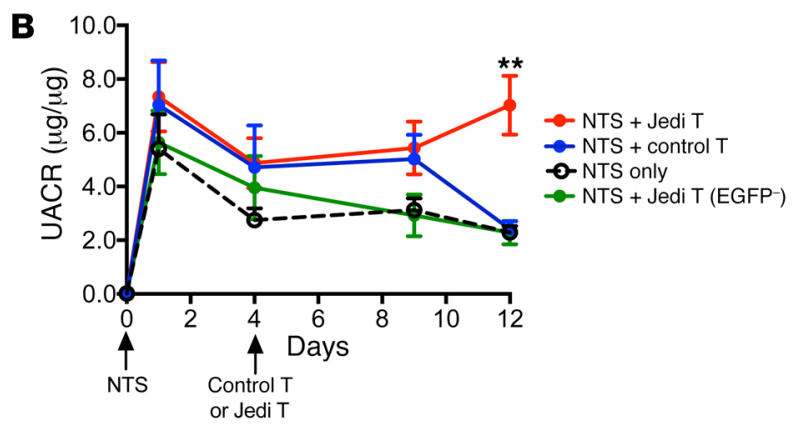

C
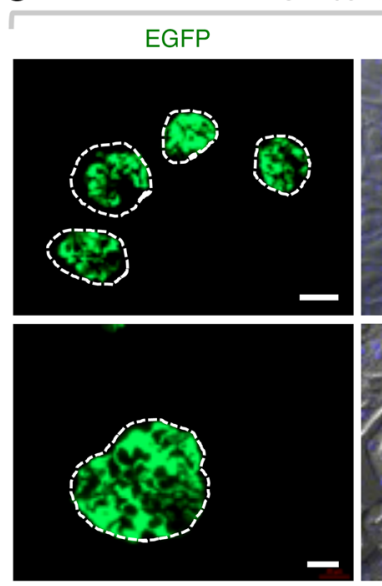

D

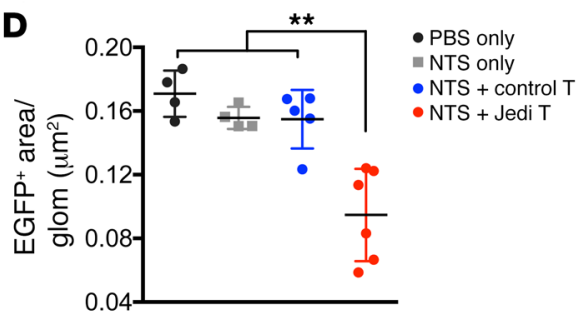
EGFP DIC DAPI
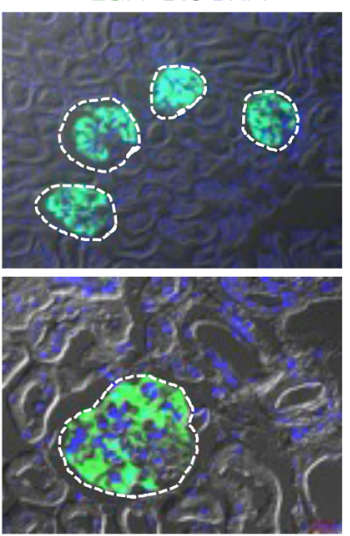
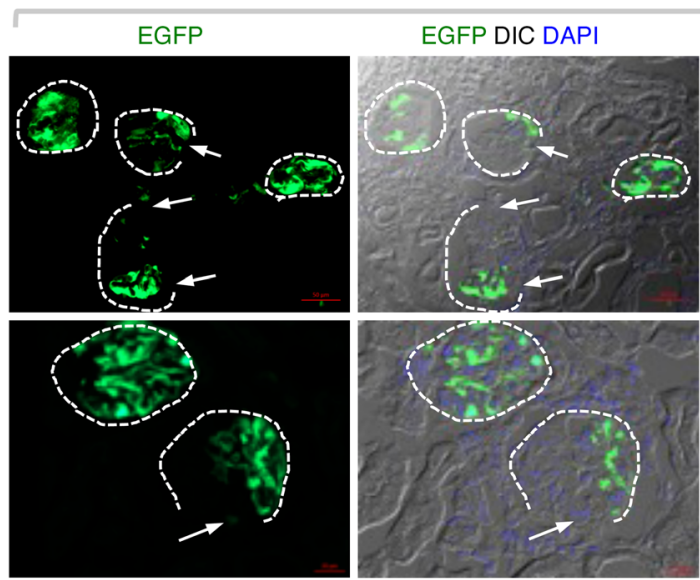

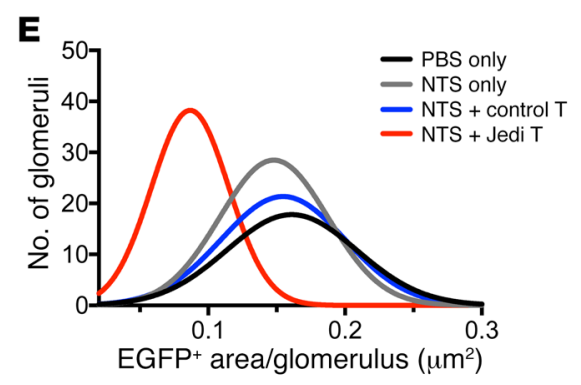

Figure 2. Effects of Jedi T cell injections in the setting of NTSN. (A) Time course for the experimental protocol. Four days after injection of NTS (0.1 ml), pod-EGFP mice were coinjected with LV.EGFP and either control T cells $(n=5)$ or Jedi T cells $(n=6)$. Mice with NTS injection only $(n=8)$ and EGFP- WT injected with Jedi T cells (NTS plus Jedi T cell; EGFP-) $(n=6)$ served as controls. (B) Following NTS injection, urinary albumin-to-creatinine ratios increased initially in all groups, but slowly declined over time in all groups, with the exception of the NTS plus Jedi T cell group. ${ }^{* *} P<0.01$ when compared with all other groups by ANOVA with Bonferroni's modification for multiple comparison. (C) Representative EGFP fluorescence images of kidneys from mice. Original magnification, $\times 200$ (top row); $\times 400$ (bottom row). Scale bars: $50 \mu \mathrm{m}$ (top row); bottom row: $20 \mu \mathrm{m}$ (bottom row). Dotted lines indicate the BC, with arrows pointing to the sites of ruptures. ( $\mathbf{D}$ and $\mathbf{E})$ Quantification of the EGFP ${ }^{+}$area in pod-EGFP mice, as EGFP+ area per glomerulus (D) and size distribution curves for EGFP+ area per glomerulus (E) ( $n=4$ mice, 381 glomeruli analyzed for PBS-only group; $n=4$ mice, 471 glomeruli analyzed for NTS-only group; $n=5$ mice, 539 glomeruli analyzed for NTS plus control T cell group; and $n=6,649$ glomeruli analyzed for NTS plus Jedi T cell group). ${ }^{* *} P<0.01$, compared with all other groups by ANOVA with Bonferroni's correction for multiple comparisons.

proteinuria (Figure 2B). Subsequently, albuminuria declined over the next 11 days in NTS only (as previously reported for this model; refs. 25, 26) and in the NTS plus control T cell-injected group. In contrast, injection of NTS plus Jedi T cells caused a second significant and sustained rise in albuminuria (Figure 2B). Moreover, blood urea levels at the time of euthanasia (12 days after NTS injections) increased significantly in all NTSN groups over control levels, but were highest in the NTS plus Jedi T cell-injected group (Table 1). Thus, the injection of activated Jedi $\mathrm{T}$ cells in pod-EGFP mice with NTSN caused a significant $(P<0.01)$ worsening of glomerular function, as determined by both increases in proteinuria and blood urea levels. The injection with LV.EGFP did not result in activation of control $\mathrm{T}$ cells, which are polyclonal and do not recognize EGFP (21). Therefore, to rule out the potential effects of activated $\mathrm{T}$ cells independently of antigen specificity, we introduced another experimental group of WT mice without EGFP expression in podocytes, in which NTSN was induced and, after 4 days, Jedi $\mathrm{T}$ cells and LV.EGFP were injected (NTS plus Jedi T cells; EGFP-). In this group, Jedi $\mathrm{T}$ cells were activated by LV.EGFP in an identical manner to those in the pod-EGFP mice, but could not find their cognate antigen in podocytes of WT mice, as these lack EGFP expression. Any effects observed by injection of NTS 
A
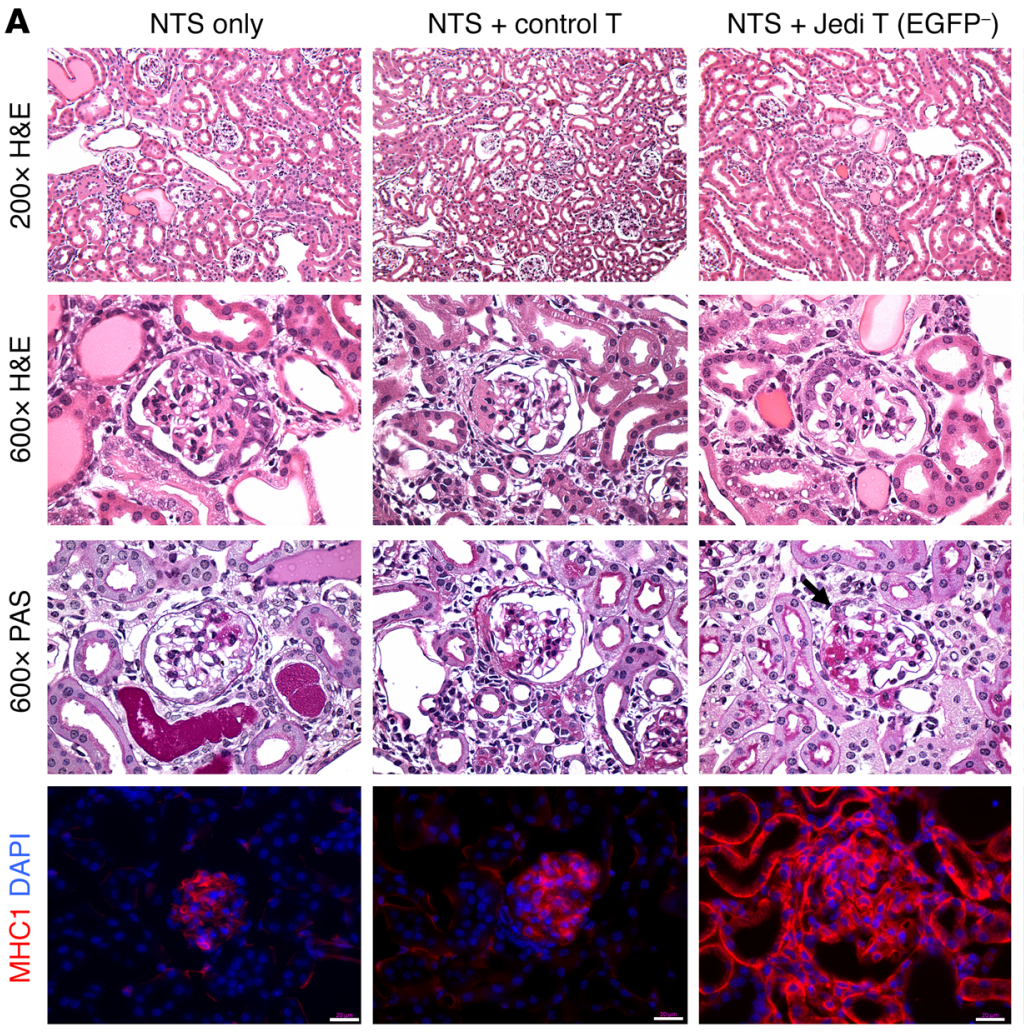

B

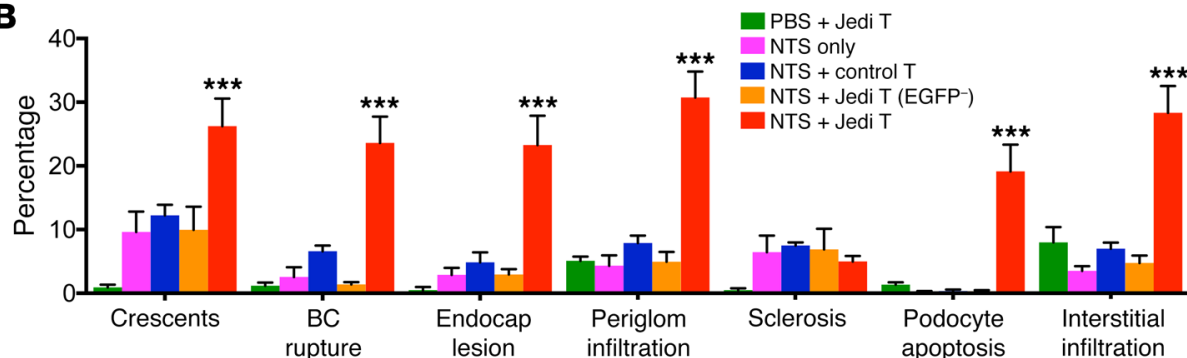

$\mathrm{NTS}+$ Jedi T
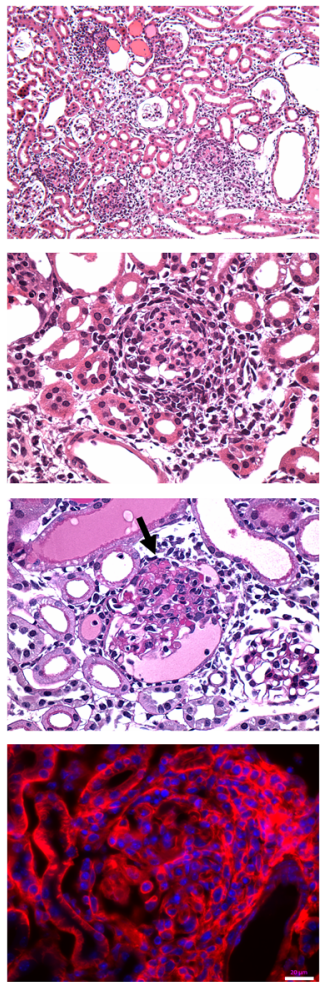

Figure 3. Histopathological analysis of mouse kidneys. (A) Representative images of H\&Eand PAS-stained kidneys from mice injected with NTS. Destruction of glomeruli with inflammatory infiltrates and apoptosis and massive pathological worsening with defects in BC are apparent in kidneys of NTS plus Jedi T cell-injected mice. BC rupture is indicated by black arrows in PAS images. Bottom panel shows the immunofluorescence of $\mathrm{MHC}-\mathrm{I}$ in all groups. Original magnification, $\times 200$ (top row); $\times 600$ (second and third rows); $\times 400$ (bottom row).

(B) Quantification of histopathology from 90 to 170 glomeruli per kidney section for each mouse of the 4 to 6 mice per group. ${ }^{* *} P$ $<0.001$, compared with all other groups by ANOVA with Bonferroni's correction for multiple comparisons. plus Jedi T cells in WT (EGFP-) mice would therefore indicate other nonspecific inflammatory effects of activated Jedi T cells. As shown in Figure 2B, NTS plus Jedi T cells (EGFP-) mice developed an initial course of proteinuria, followed by a slow return to baseline, similar to that observed in the NTS only or NTS plus control $\mathrm{T}$ cell experimental groups. Likewise, blood urea levels were comparable to those in NTS only or NTS plus control T cell groups and significantly $(P<0.01)$ lower than in NTS plus Jedi T cell groups. Therefore, injection of activated Jedi T cells by itself did not result in any exacerbation of albuminuria when $\mathrm{T}$ cells did not recognize any podocyte-specific antigen (Figure 2B).

Histopathological changes. By histopathological analysis, kidneys of mice injected with either NTS only or NTS plus control T cells showed mild to moderate crescentic GN with some periglomerular and interstitial infiltrates (Figure 3A). NTS plus Jedi T cell (EGFP') mouse kidneys also showed comparable results to those of NTS only and NTS plus control T cell-injected groups (Figure 3A). In contrast, NTS plus Jedi T cell injection in $\mathrm{EGFP}^{+}$mice showed severe RPGN histology (Figure 3A and Supplemental Figure 3A). Semiquantitative, blinded evaluation of the histopathology (90150 glomeruli per kidney section per mouse) showed massive lesions with significantly more crescents, endocapillary lesions, defects of BC, podocyte apoptosis, and periglomerular as well as interstitial infiltrates in the NTS plus Jedi T cell group as compared with either NTS only, NTS plus control T cell, or NTS plus Jedi T cell (EGFP-) groups (Figure 3B). In addition to the identification of cell death by the typical histopathological changes, apoptosis was also confirmed by TUNEL staining (Supplemental Figure 3B). In order to verify that defects in BC evaluated on single standard histological sections $(3 \mu \mathrm{m})$ were representative of a more complete view of a glomerulus, we examined 15 serial sections $(6 \mu \mathrm{m})$ per kidney in 2 mice of the NTS plus Jedi T cell group and evaluated the percentage of $\mathrm{BC}$ lesions on all glomeruli present per section (180-240 per section; see Methods). For each mouse, the percentage of glomeruli with ruptured $\mathrm{BC}$ was rather consistent at $11 \%-$ $16 \%$ and $16 \%-22 \%$ per section, respectively, with around 4,000 total glomeruli evaluated per mouse kidney (Supplemental Table 1). Of note, these results are in the same range as those noted by the pathologist's evaluation at $24 \% \pm 8 \%$ (Figure $3 \mathrm{~B}$ ).

Consistent with previous reports $(23,24)$, injection of NTS resulted in upregulation of glomerular MHC-I immunofluorescence staining in all groups (Figure 3A). However, this did not 
A
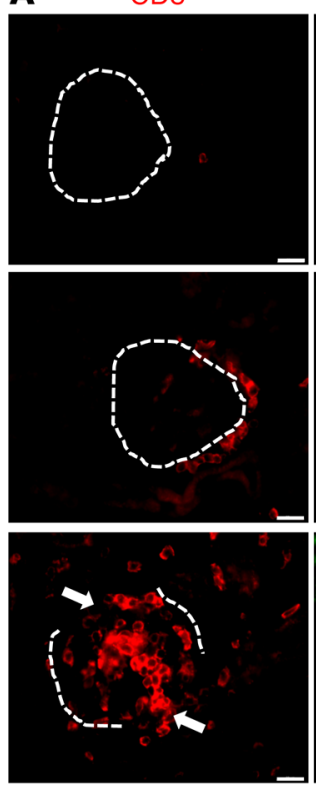

CD45.1
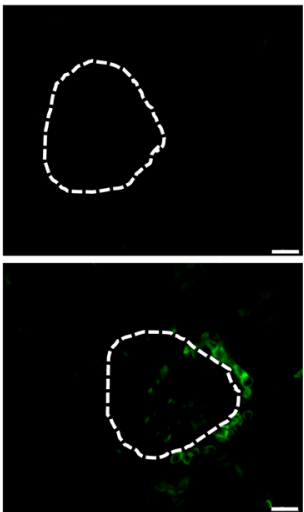
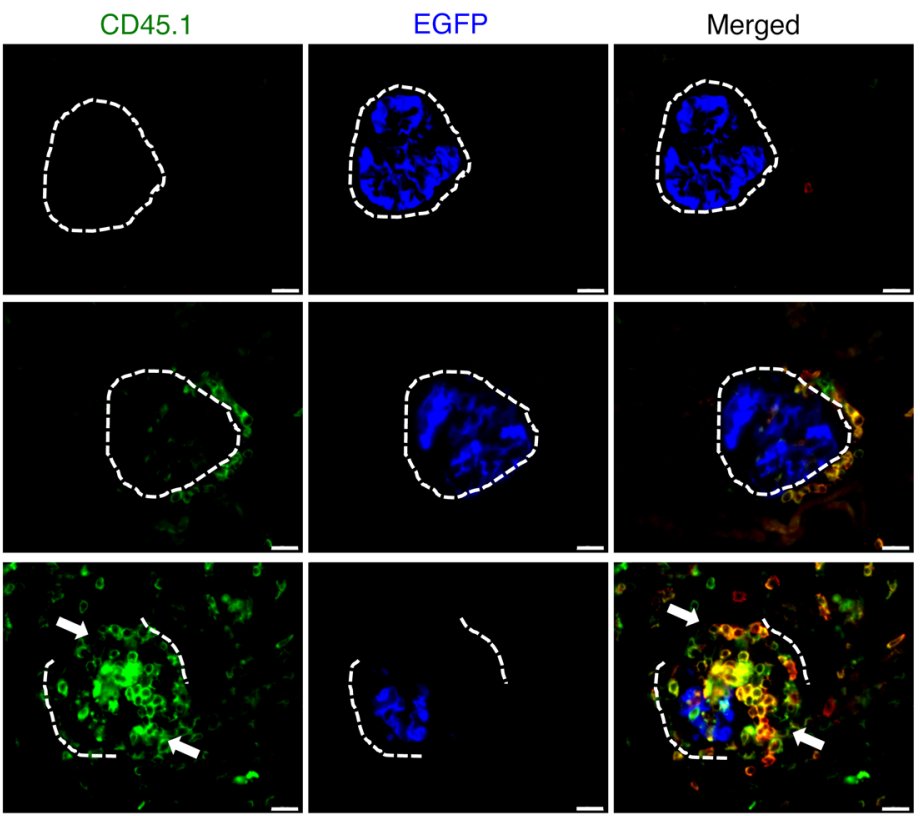
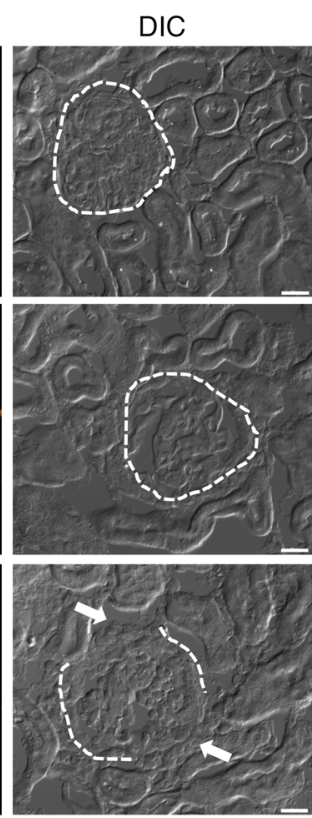
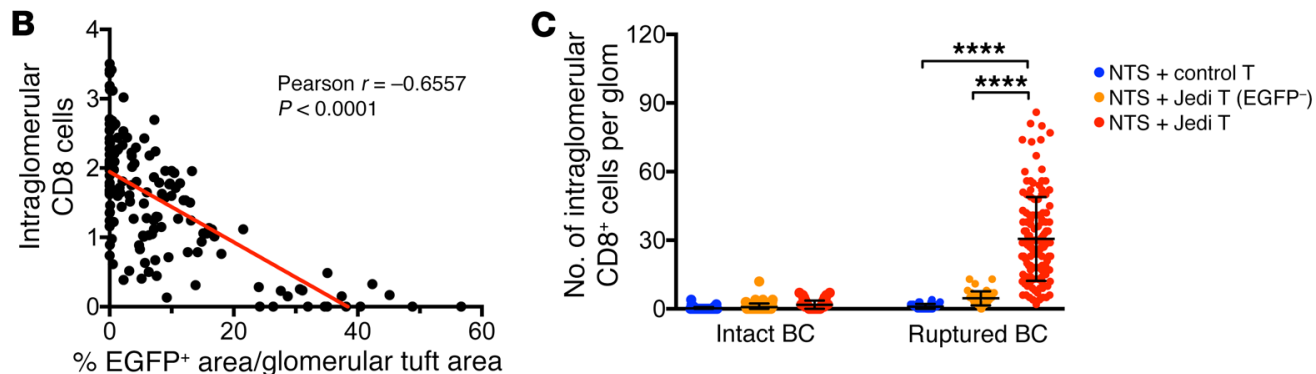

Figure 4. Effects of BC rupture on CD8/Jedi T cell infiltrations of glomerular space and EGFP+ podocytes. (A) Frozen kidney sections were immunostained for all CD8+ (red) and Jedi CD45.1 (green) T cells. EGFP+ podocytes were pseudocolored in blue to allow separation from the CD8/CD45.1 T cells. Merged images show costaining of Jedi CD45.1 $1^{+}$and CD8 ${ }^{+}$T cells. Differential interference contrast allows identification of glomeruli and BC. Ruptures in the BC are indicated by white arrows. Original magnification, $\times 400$. (B and C) Quantification of intraglomerular CD8 ${ }^{+} \mathrm{T}_{\text {cells }}$ and EGFP+ ${ }^{+}$podocyte area per glomerulus from NTS plus Jedi T cell group ( $n=6$ mice, 150 glomeruli analyzed). Pearson's correlation of the number of intraglomerular CD8 ${ }^{+}$T cells and the EGFP ${ }^{+}$ podocytes area/per glomerular tuft area (B) shows a significant inverse correlation between infiltrating CD8 ${ }^{+} \mathrm{T}_{\text {cells }}$ and the remaining percentage of EGFP+ podocyte area. Quantification of CD8+ T cells in glomeruli with or without BC rupture (C). ${ }^{* * *} P<0.0001$, compared between indicated groups by ANOVA with Bonferroni's correction for multiple comparisons.

result in loss of podocytes when the antigen recognized by the activated $\mathrm{T}$ cells was not present in podocytes, indicating again that direct contact of antigen-specific $\mathrm{T}$ cells with podocytes is necessary for podocyte elimination.

\section{Morphometric evaluation of podocyte area during NTSN}

The podocyte-specific EGFP expression in the transgenic mice allowed us to easily determine podocyte area by EGFP signal, as previously detailed by us (22). Figure $2 \mathrm{C}$ shows the representative high and low magnification images of EGFP expression in glomeruli of NTS plus control T cell and NTS plus Jedi T cell groups, with marked loss of glomerular EGFP areas in the latter group. Morphometric analysis of glomerular podocyte $\mathrm{EGFP}^{+}$area showed that NTS alone or NTS plus control T cell injection resulted in only a slight, not significant, decrease in the glomerular $\mathrm{EGFP}^{+}$area (Figure 2, C-E). In contrast, NTS plus Jedi T cell injection significantly reduced the $\mathrm{EGFP}^{+}$area when expressed either as size distribution curve (Figure 2E) or as mean area obtained for entire kidney sections (Figure 2D). Interestingly, glomeruli with crescents, and especially ruptures or loss of $\mathrm{BC}$, had the most pronounced loss of $\mathrm{EGFP}^{+}$podocyte area (Figure $2 \mathrm{C}$ ), suggesting that intact capsules prevented Jedi $\mathrm{T}$ cells from attacking podocytes. The loss of podocytes by EGFP area could not be determined in the NTS plus Jedi $\mathrm{T}$ cell $\left(\mathrm{EGFP}^{-}\right)$mice, but the lack of proteinuria worsening after NTS injection or glomerular pathology, including podocyte apoptosis (Figure 3B), renders loss of podocytes in this group extremely unlikely. Thus, in NTSN, the injection of Jedi T cells results in loss of $\mathrm{EGFP}^{+}$podocyte areas in the glomeruli, consistent with Jedi $\mathrm{T}$ cells injuring the $\mathrm{EGFP}^{+}$podocytes and causing their depletion with deterioration of glomerular function by increased proteinuria and BUN values (Figure 2B and Table 1).

\section{Glomerular infiltration with Jedi T cells correlates with loss of EGFP+} podocyte area

To assess a correlation between infiltration of Jedi $\mathrm{CD} 8^{+} \mathrm{T}$ cells and podocyte damage, we determined the extent of $\mathrm{CD}^{+} \mathrm{T}$ cell 
A
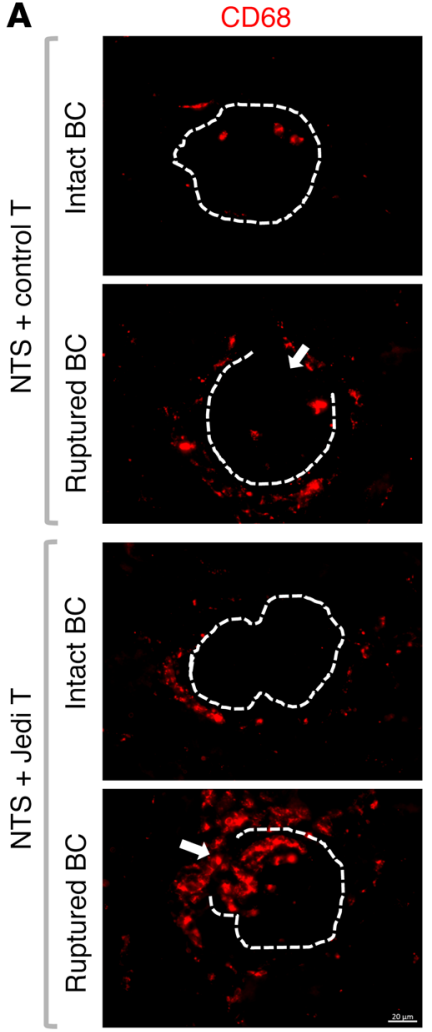

B

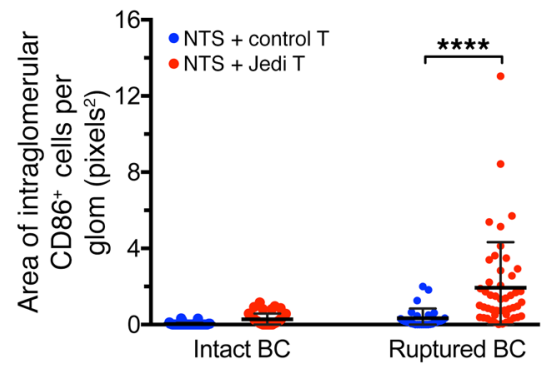

CD68 EGFP DAPI
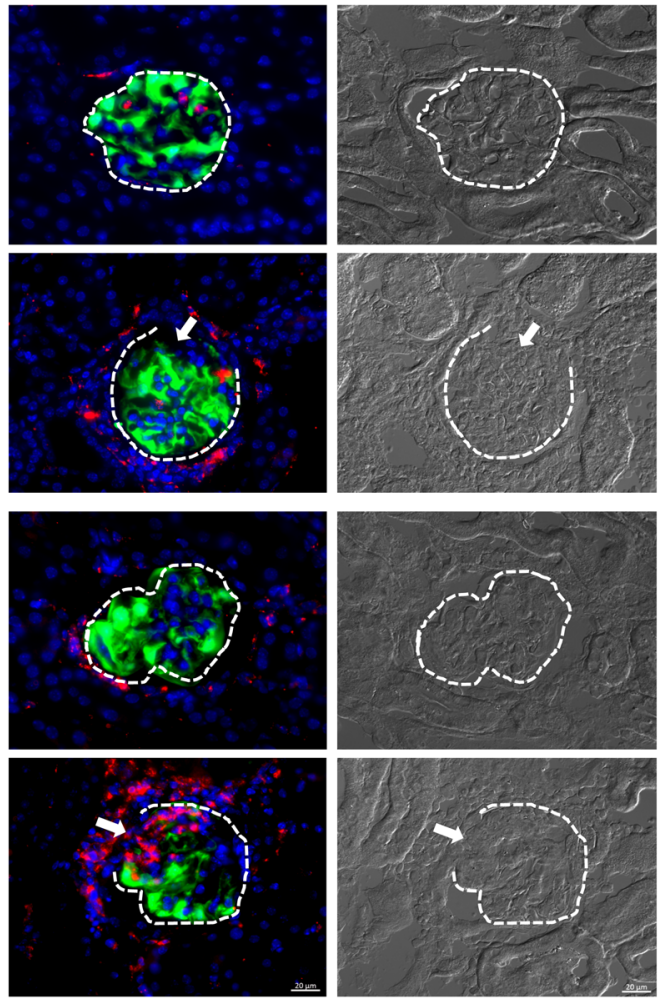
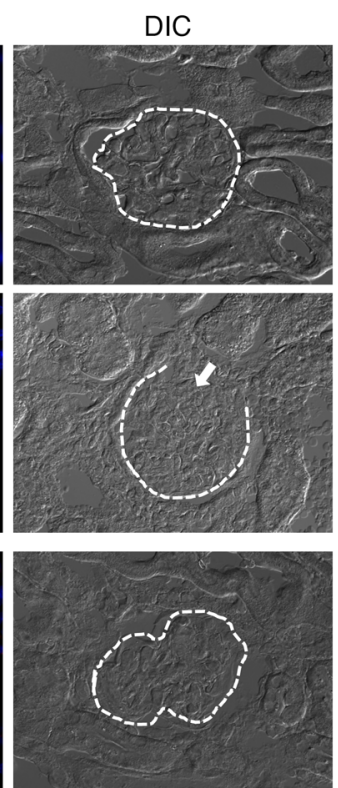

infiltration and loss of $\mathrm{EGFP}^{+}$area per glomerulus. Consistent with histopathological analysis shown in Figure 3B, there were significantly more $\mathrm{CD}^{+}$infiltrates in the kidneys of the NTS plus Jedi T cell group than in the NTS plus control T cell group (Figure $4, \mathrm{~A}$ and $\mathrm{C})$. By double staining for CD8 to identify $\mathrm{CD} 8^{+} \mathrm{T}$ cells and CD45.1 to identify donor Jedi cells, we could observe that over $90 \%$ of the infiltrating $\mathrm{CD} 8^{+} \mathrm{T}$ cells were in fact $\mathrm{CD} 45.1^{+} \mathrm{Jedi} \mathrm{T}$ cells in the NTS plus Jedi T cell group (Figure 4A). Moreover, we could confirm that the glomeruli in which the EGFP $\mathrm{EP}^{+}$podocyte area was reduced were also concomitantly infiltrated by $\mathrm{CD} 45.1^{+} \mathrm{CD} 8^{+}$Jedi $\mathrm{T}$ cells both inside and around $\mathrm{BC}$.

Infiltrating Jedi $\mathrm{T}$ cell numbers per glomerulus and EGFP' area within the same glomerulus showed an inverse correlation, consistent with Jedi $\mathrm{T}$ cell infiltration leading to podocyte loss (Figure 4B), as also seen by light microscopy (Figure 3B). Direct interactions of Jedi $\mathrm{T}$ cells with the $\mathrm{EGFP}^{+}$podocytes could be demonstrated by 3D fluorescent deconvolution microscopy (Supplemental Video 1), consistent with Jedi T cells directly interacting and attacking $\mathrm{EGFP}^{+}$podocytes. In addition, detached EGFP+ podocytes were also observed within the glomerular urinary space or inside tubular lumina (Supplemental Figure 3C).
Figure 5. Effects of $B C$ rupture on glomerular localization of CD68 macrophages. (A) Representative immunostained images of $\mathrm{CD}^{\circ} 8^{+}$macrophages in glomeruli with intact versus ruptured BC. Ruptured $\mathrm{BC}$ is associated with an increase in $\mathrm{CD}^{+} 8^{+}$macrophages infiltrating the glomerular space (indicated by white arrows). Original magnification, $\times 400$. (B) Quantification of intraglomerular CD68 ${ }^{+}$area for intact versus ruptured $\mathrm{BC}$ ( $n=53$ glomeruli for intact, $n=29$ glomeruli for ruptured BC in NTS plus control T cell group; $n=51$ glomeruli for intact, $n=48$ ruptured $\mathrm{BC}$ in NTS plus Jedi T cell group). ${ }^{* * *} P<0.0001$, compared between indicated groups by paired $t$ test.

Jedi T cells only accumulate inside the glomeruli with ruptured BC

Quantification of $\mathrm{CD}^{+} \mathrm{T}$ cells within each glomerulus was performed in glomeruli with intact versus disrupted BC (Figure 4C). We determined the integrity of the capsule by PAS staining and by differential interference contrast microscopy. Notably, only glomeruli with crescents and breaks in the $\mathrm{BC}$ displayed the infiltration of $\mathrm{CD}^{+} \mathrm{T}$ cells within the capsule space (Figure 4A). In glomeruli with intact BC, Jedi CD8 ${ }^{+}$ $\mathrm{T}$ cells only accumulated around BC and did not interact with $\mathrm{EGFP}^{+}$podocytes (Figure $4 \mathrm{~A}$ ).

$\mathrm{CD68}^{+}$macrophages also accumulate mostly inside glomeruli with ruptured $\mathrm{BC}$

A major role for macrophage infiltration around and inside $\mathrm{BC}$ has also been established for both experimental crescentic NTSN and in biopsies from patients with RPGN of various etiologies (4-6). We therefore also determined the presence of $\mathrm{CD} 68^{+}$macrophages in the NTS plus control T cell and NTS plus Jedi T cell groups (Figure 5). Activated macrophages are characterized by many cell extensions, making it difficult to count these cells, as the $\mathrm{CD} 68^{+}$areas cannot easily be attributed to a specific macrophage. We therefore determined $\mathrm{CD} 8^{+}$areas by computer-assisted morphometry (as previously described; ref. 27) for the glomerular areas with intact or ruptured $\mathrm{BC}$. While a few $\mathrm{CD} 68^{+}$cells were noted in glomeruli with intact $\mathrm{BC}$, significantly larger $\mathrm{CD} 68^{+}$areas were observed in glomeruli with ruptured BC (Figure 5, A and B). Thus, these results suggest that breaches in $\mathrm{BC}$ facilitated infiltration of both activated antigen-specific $\mathrm{CD} 8^{+} \mathrm{T}$ cells and $\mathrm{CD} 68^{+}$macrophages into the glomerular space.

\section{Proliferation of peri- and intraglomerular $\mathrm{CD}^{+} \mathrm{T}$ cells}

To evaluate local proliferation of Jedi T cells around and inside the glomeruli, we double stained for $\mathrm{CD}^{+}$to label Jedi $\mathrm{T}$ cells and for $\mathrm{Ki}-67$ as a marker of proliferating cells. In glomeruli with intact BC, $\mathrm{Ki}-67^{+} \mathrm{CD} 8^{+}$cells were identified mostly in a periglomerular distribution where most $\mathrm{T}$ cells were located (Figure $6, \mathrm{~A}-\mathrm{C}$ ). Similarly, glomeruli with ruptured $\mathrm{BC}$ had $\mathrm{Ki}-67^{+} \mathrm{CD}^{+}$cells mostly in a periglomerular distribution and, to a lesser degree, also in the glomeru- 
A
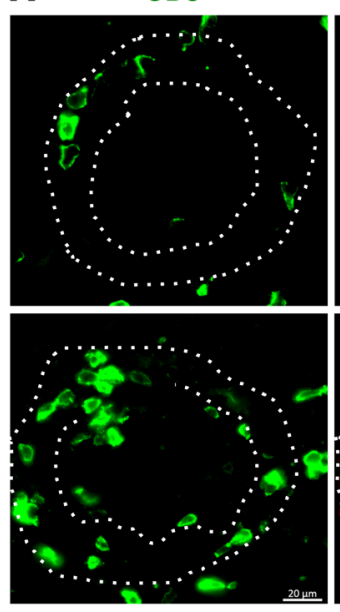

B
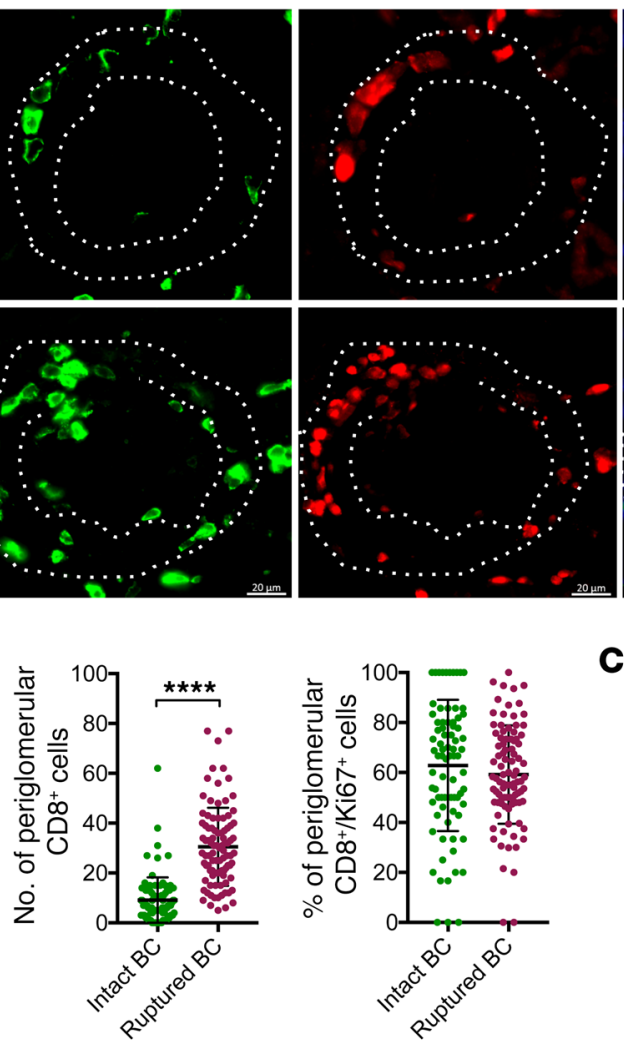

CD8 Ki-67 DAPI

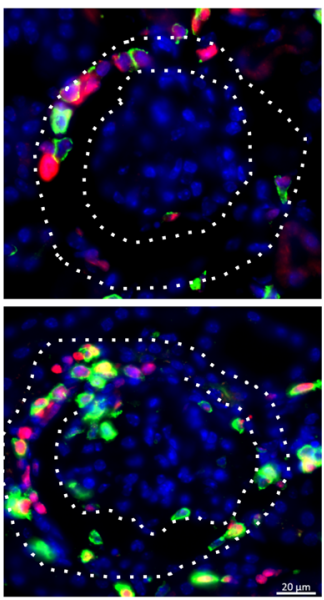

EGFP DIC
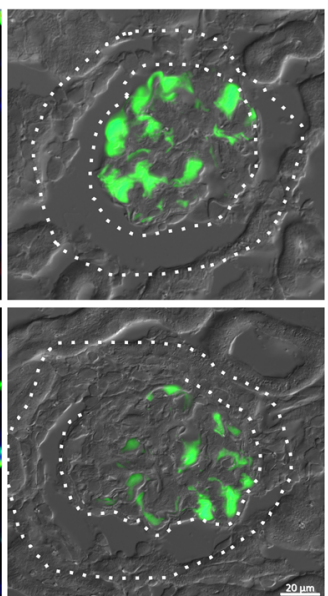

Figure 6. Effects of BC rupture on the distribution of proliferating $\mathrm{CD8}^{+} \mathbf{T}$ cells. (A) Proliferation of peri- and intraglomerular $\mathrm{CD}^{+}$ $T$ cells was evaluated by double immunostaining with $\mathrm{Ki}-67$. Inner dotted line indicates the $B C$ and outer line the limits of periglomerular infiltrates. Original magnification, $\times 400$. (B and C) Quantification of periglomerular (B) and intraglomerular (C) numbers of $\mathrm{CD}^{+}$and percentages of $\mathrm{CD} 8^{+} \mathrm{Ki}-67^{+}$cells in glomeruli with intact or ruptured $B C$ ( $n=88$ glomeruli with intact BC, $n=$ 94 glomeruli with ruptured $B C$ from 2 different NTS plus Jedi T cellinjected mice). ${ }^{* * *} P<0.0001$. lar space (Figure 6, B and C). The periglomerular Ki- $67^{+} \mathrm{CD} 8^{+}$cells constituted $63 \%$ of $\mathrm{CD}^{+} \mathrm{T}$ cells in glomeruli with intact $\mathrm{BC}(n=88)$ and $59 \%$ of $\mathrm{CD}^{+} \mathrm{T}$ cells in glomeruli with disrupted BC $(n=94)$. The intraglomerular $\mathrm{Ki}-67^{+} \mathrm{CD}^{+}$cells were similar at $61 \%$ in glomeruli with intact BC and 55\% with ruptured BC. Overall, both the periglomerular and intraglomerular $\mathrm{CD}^{+} \mathrm{T}$ cells increased with the disruption of $\mathrm{BC}$, and about $60 \%$ of them were proliferating.

\section{Cytotoxic $\mathrm{CD8}^{+} \mathrm{T}$ cells also infiltrate the glomerular space in biopsies} from patients with crescentic RPGN, especially at sites of breaches in BC To verify that these observations, obtained in murine crescentic NTSN as a model of human anti-GBM nephritis, may also apply to human RPGN, we analyzed 25 human biopsies, randomly chosen from patients with crescentic GN of various etiologies, and as controls, 7 with membranous GN, for glomerular CD8 ${ }^{+} \mathrm{T}$ cell infiltration (Supplemental Table 2 and Figure 7). The data from 7 biopsies, each with anti-GBM nephritis (117 glomeruli analyzed) and with ANCA-GN (123 glomeruli analyzed), showed 80\%-83\% crescents. In glomeruli with crescents and ruptures of BC, $56 \%$ and $59 \%$, respectively, were associated with glomerular $\mathrm{CD}^{+} \mathrm{T}$ cell infiltration. In contrast, for glomeruli with intact BC only $6 \%$ and $3 \%$, respectively, showed infiltration with $\mathrm{CD} 8^{+} \mathrm{T}$ cells. Biopsies from 6 cases of IgA nephropathy showed crescents in $42 \%$ of cases, with $9 \% \mathrm{CD}^{+}$infiltrates in glomeruli with ruptured $\mathrm{BC}$ and only $4 \%$ in those with intact BC. For acute postinfectious GN, the amount of glomeruli with crescents was $14 \%$ and that of the CD8 ${ }^{+}$ $\mathrm{T}$ cell infiltrates was $6 \%$ with ruptured and $2 \%$ with intact BC. As expected, biopsies from membranous GN contained essentially no $\mathrm{CD}^{+} \mathrm{T}$ cells in glomeruli.
As shown by representative histologic images in Figure 7, A-F, $\mathrm{CD}^{+}$cells tend to aggregate around glomeruli, especially those containing crescents, from which sites they enter crescents and Bowman's space through localized defects in BC. They infiltrate the crescent and can also be seen occasionally adjacent to podocytes on the glomerular tuft. In ANCA-GN, a prominent interstitial $C D 8^{+}$infiltrate was also noted, perhaps reflecting the more diffuse microvasculitis of this disease.

Taken together, the results expand on previous observations of occasional CD8 ${ }^{+} \mathrm{T}$ cell infiltrations in crescentic GN (8-15) and support our experimental data in the NTSN model. They are also consistent with the hypothesis that breaches in $\mathrm{BC}$ can provide access of $\mathrm{CD}^{+} \mathrm{T}$ cells to the glomerulus. Therefore, they allow expansion of our hypothesis derived from experimental NTSN to human crescentic GN, especially anti-GBM nephritis and ANCA-GN.

\section{Discussion}

Evidence for the involvement of cellular immunity in various forms of GN is becoming increasingly apparent. In crescentic GN of various etiologies, the role of macrophages, DCs, and polymorphonuclear leukocytes is well established (3-6). Furthermore, the involvement of several types of $\mathrm{CD} 4^{+} \mathrm{T}$ cells during crescentic GN has been extensively studied $(3,4)$, but the role of $\mathrm{CD}^{+} \mathrm{T}$ cells still remains unclear, in part because of lack of adequate tools (18). The potential of cytotoxic $\mathrm{CD} 8^{+} \mathrm{T}$ cells to interact with glomerular cells and especially podocytes would be of considerable interest, as podocyte injury and loss result in proteinuria and loss of glomerular filtration. In order to address this, we took advantage of our transgenic mice that express EGFP specifically in podocytes 

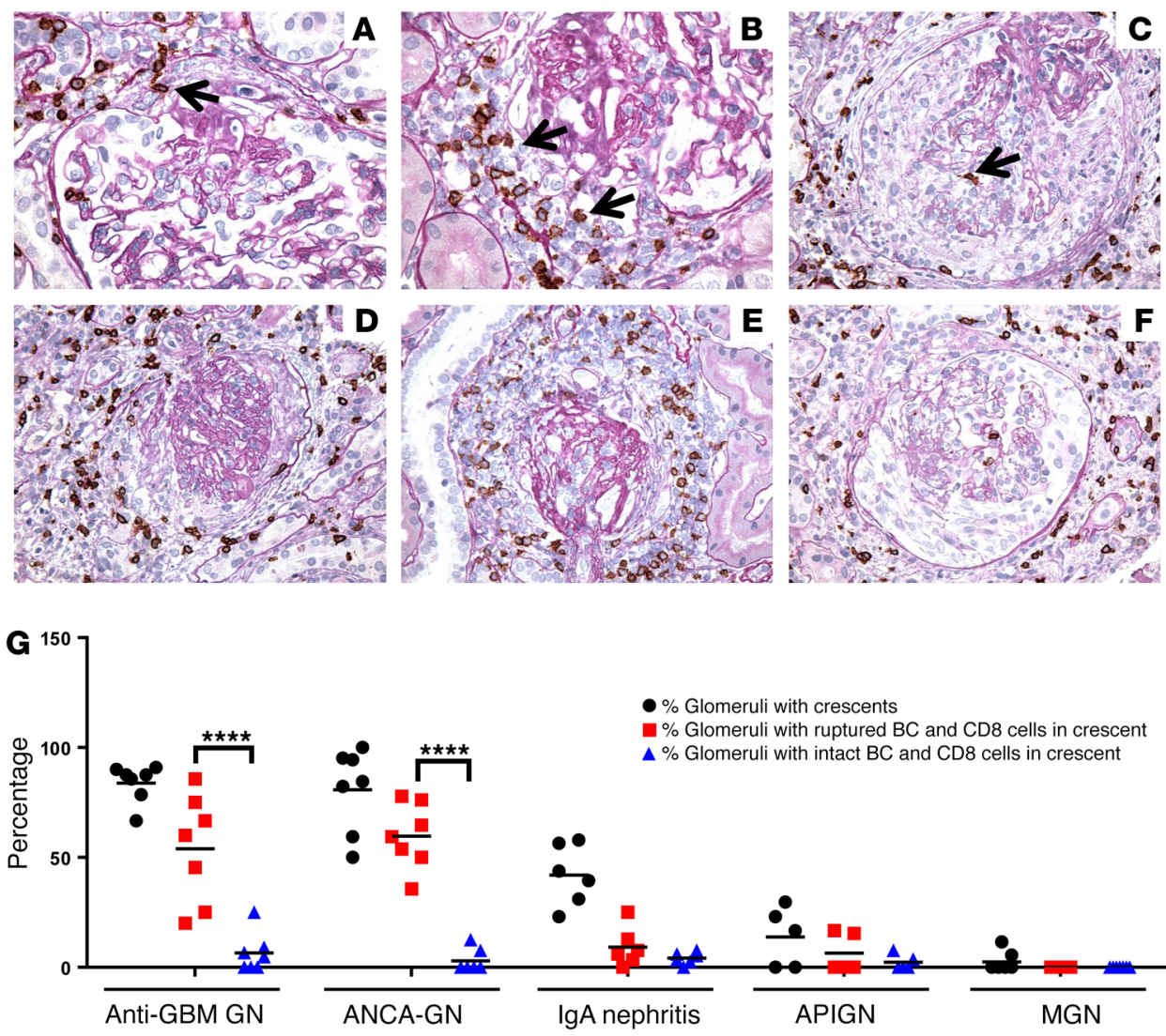

Figure 7. Immunohistologic analysis of CD8 in human biopsies with anti-GBM nephritis and ANCA-CN.

(A-F) Representative images of CD8 immunohistochemistry. (A) $C D 8^{+}$cells originating from the periglomerular interstitium infiltrate a cellular crescent through discrete ruptures of BC (arrow). PAS counterstain. Original magnification, $\times 600$. (B) CD8 ${ }^{+}$cells (arrows) penetrate a cellular crescent through multiple small breaks in $\mathrm{BC}$, which appears fragmented and discontinuous. PAS counterstain. Original magnification, $\times 600$. (C) A CD8 cell located deep within a crescent overlies a GBM, suggesting direct podocyte contact (arrow). PAS counterstain. Original magnification, $\times 600$. (D) BC has a broad rupture involving more than half the glomerular circumference, associated with abundant $\mathrm{CD} 8^{+}$cells infiltrating the crescent from the adjacent interstitium. PAS counterstain. Original magnification, $\times 400$. (E) A glomerulus with complete destruction of BC shows circumferential infiltration of its cellular crescent by numerous CD8 ${ }^{+}$cells and merging of the crescent with the adjacent interstitium. PAS counterstain. Original magnification, $\times 400$. (F) A glomerulus with intact $B C$ has no infiltrating $\mathrm{CD}^{+}$cells within its cellular crescent despite many $\mathrm{CD} 8^{+}$cells in the periglomerular interstitium. A single circulating $\mathrm{CD}^{+}$cell is present in a glomerular capillary. PAS counterstain. Original magnification, $\times 400$. (C) Quantification of percentage of glomeruli with crescents, with ruptured BC with CD8 cells in the crescents, or with intact BC with CD8 cells in the crescents. APIGN, acute postinfectious glomerulonephritis; MGN, membranous glomerulonephritis. ${ }^{* * *} P<0.0001$.

(pod-EGFP) (22) and combined this with a recently generated mouse strain, in which $\mathrm{CD} 8^{+} \mathrm{T}$ cells specifically recognize EGFPexpressing cells, termed Jedi mice (21). We had shown that injected Jedi T cells can efficiently kill a variety of cell types in vivo (21). We now used Jedi $\mathrm{T}$ cells to assess their potential for killing of EGFP ${ }^{+}$ podocytes in pod-EGFP mice. The EGFP expression restricted to podocytes allowed us to quantitate glomerular EGFP as a direct measure of the area of glomerular podocytes (22). Surprisingly, in control conditions and despite podocytes expressing both MHC-I and EGFP, Jedi $\mathrm{T}$ cells were not capable of infiltrating the glomeruli of pod-EGFP mice or of altering the glomerular function, as determined by blood urea levels and lack of proteinuria. The lack of activated Jedi $\mathrm{T}$ cells to interact with the $\mathrm{EGFP}^{+}$podocytes was all the more surprising, as the Jedi $\mathrm{T}$ cells totally eliminated the
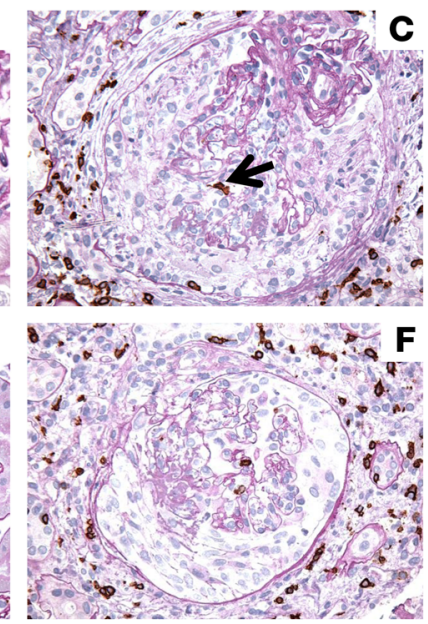

EGFP $^{+}$splenocytes transduced by the LV.EGFP lentivirus. Our results indicated that $\mathrm{CD}^{+}{ }^{+} \mathrm{T}$ cells are not able to access and attack podocytes in healthy mice, even when carrying a $T$ cell receptor that recognizes antigen in podocytes and even when fully activated. These results are consistent with observations by Heymann et al., who showed that, while antigen from podocytes activated $\mathrm{CD} 8^{+} \mathrm{T}$ cells in the draining lymph node and that these then migrated to the glomeruli, they only accumulated around the glomeruli, but did not access the target podocytes inside BC (18). Of note, these authors also showed that injection of podocyte-specific $\mathrm{CD} 8^{+}$ $\mathrm{T}$ cells only resulted in their periglomerular accumulation without any invasion of Bowman's space, glomerular pathology, and loss of podocytes. In both this study and in our initial experiments, it remained unclear why the $\mathrm{CD} 8^{+} \mathrm{T}$ cells could not attack their podocyte target.

The failure of cytotoxic $\mathrm{T}$ cells to directly attack podocytes was in contrast to previous observations of $\mathrm{CD}^{+} \mathrm{T}$ cells interacting with glomerular endothelial cells that expressed their cognate antigen $(19,28)$. In very elegant experiments, these authors showed that the glomerular endothelium was recognized and attacked by $\mathrm{CD} 8^{+} \mathrm{T}$ cells, which resulted in a GN similar to microvasculitis. Moreover, contribution of the $\mathrm{CD} 8^{+} \mathrm{T}$ cells to the glomerular capillary disease was further supported by attenuation of the disease by $\mathrm{CD} 8^{+} \mathrm{T}$ cell depletion (19). It should be noted that, in all of these studies, the inflammatory infiltrate remained restricted to glomerular intracapillary sites. Even when segmental capillary necrosis was observed, there was no evidence for extravasation of $\mathrm{CD} 8^{+} \mathrm{T}$ cells into Bowman's space or direct interactions with podocytes or formation of crescents (19). Thus, podocytes, in contrast to glomerular endothelial cells, appear to be protected from $\mathrm{CD} 8^{+} \mathrm{T}$ cells. However, the question remains: what prevents podocyte-specific, cytotoxic $\mathrm{CD} 8^{+} \mathrm{T}$ cells from penetrating into Bowman's space to attack their target podocytes, thereby generating a physically protected niche?

We therefore considered the possibility that the fibrous strandstrengthened basement membrane of $\mathrm{BC}$ (29) might serve as a barrier for $\mathrm{CD} 8^{+} \mathrm{T}$ cell invasion. Therefore, an initial insult to the glomerulus and $\mathrm{BC}$ might be required in order for cytotoxic $\mathrm{CD} 8^{+} \mathrm{T}$ cells to target podocytes. We therefore induced a mild model of NTSN in 
pod-EGFP mice. Injection of Jedi T cells - but not of control CD8 ${ }^{+} \mathrm{T}$ cells - caused a significant $(P<0.01)$ exacerbation of the NTSN in pod-EGFP mice. In contrast, when activated Jedi $T$ cells were injected in WT mice without EGFP expression in podocytes with NTSN, the nephritis was comparable to that observed in pod-EGFP mice with only NTS injection or with NTS and control T cell injection. The acceleration of the disease by Jedi $T$ cell injection in pod-EGFP mice was demonstrated by the worsening of the histopathology, proteinuria, urea blood levels, and the loss of $\mathrm{EGFP}^{+}$podocyte area. Observations of direct contact of Jedi T cells with $\mathrm{EGFP}^{+}$podocytes, along with an inverse relationship between the number of intraglomerular Jedi T cells and the remaining $\mathrm{EGFP}^{+}$podocytes, strongly indicated that Jedi $\mathrm{T}$ cells were responsible for the podocyte loss. Interestingly, we observed that glomeruli with disrupted BC presented with massive infiltration of Jedi $\mathrm{T}$ cells, which correlated with concomitant losses of podocyte $\mathrm{EGFP}^{+}$area. Consistent with our observations, in mice with experimental NTSN, increased T cell infiltration in glomeruli through ruptured $\mathrm{BC}$ has been reported in biopsies from patients with autoimmune and anti-GBM crescentic GN $(10,13)$. Experimentally, Lan et al. (20) showed in a rat model of accelerated NTSN that the accumulation of activated macrophages and $\mathrm{T}$ cells around $\mathrm{BC}$ resulted in a local crescent formation inside the capsule and, later, in defects in BC. Furthermore, in experimental animal studies and human biopsies with crescentic, autoimmune, or IgA GN, an inverse relation has been noted between the number of T cells (both $\mathrm{CD}^{+}$and $\mathrm{CD}^{+}$) in glomeruli and GFR and progression of disease (3-7, 30-32). In order to verify the infiltration of $\mathrm{CD}^{+} \mathrm{T}$ cells in human forms of crescentic GN, we examined a series of biopsies from patients with anti-GBM nephritis, ANCAGN, IgA nephropathy, acute postinfectious GN, and, as a control, membranous GN. In fact, we could confirm that $\mathrm{CD}^{+} \mathrm{T}$ cell accumulated around intact BC at sites of crescent formation (Figure 7 and Supplemental Figure 4) irrespective of the underlying etiologies. Only in glomeruli with breaches in $\mathrm{BC}$ did we observe CD8 ${ }^{+}$ $\mathrm{T}$ cells "entering" through the defect in $\mathrm{BC}$, resulting in significant accumulations of $\mathrm{CD}^{+} \mathrm{T}$ cells inside Bowman's space, mostly at sites of crescents (Figure 7). Occasionally $\mathrm{CD}^{+} \mathrm{T}$ cells were noted in close proximity to podocytes (Figure 7). Taken together, these various findings are consistent with the hypothesis that intact $\mathrm{BC}$ prevents $\mathrm{CD}^{+} \mathrm{T}$ cells from gaining access to the glomerular space, but that once $\mathrm{BC}$ is breached, $\mathrm{CD}^{+} \mathrm{T}$ cells can access the glomerular space in both experimental and human forms of crescentic GN.

Upon NTS treatment, peri- and intraglomerular accumulated Jedi CD8 ${ }^{+} \mathrm{T}$ cells displayed robust proliferation in situ. We propose that the sustained activation of glomerular cells by the NTSN and by $\mathrm{T}$ cells may induce an inflammatory state with release of cytokines and chemokines $(4,5,7)$. This may also explain why Jedi infiltration during NTSN resulted in an exacerbation of macrophage recruitment. Accumulation of $\mathrm{CD} 68^{+}$macrophages around $\mathrm{BC}$ and in the glomerular space followed a pattern similar to that of $\mathrm{CD} 8^{+} \mathrm{T}$ cells, as also occasionally observed previously in human biopsies with crescentic GN of various etiologies (8-15).

Based on these data, we propose the following model for a role of $\mathrm{CD}^{+} \mathrm{T}$ cells in the augmentation and progression of crescentic RPGN. In addition to the initial glomerular antigen-antibodymediated insult, a secondary process could generate CD8 ${ }^{+} \mathrm{T}$ cells specific for epitopes released from damaged or dying podocytes in the course of any crescentic GNs. This part of the hypothesis is based on the observation that at least some autoimmune reactions can originate from situations in which cell injury or death is mistakenly perceived as immunogenic (33). When cell death occurs during an inflammatory process (inflammatory cell death), antigen is released and taken up by DCs in an inflammatory milieu that drives activation of these DCs. Presentation of antigen by activated DCs results in activation of $\mathrm{CD} 8^{+} \mathrm{T}$ cells and, therefore, the immune response against the presented antigens (33). This response can be further facilitated by the cell injury/death and concomitant generation and release of danger-associated molecular pattern (DAMP), which activates TLR signaling. In this setting, robust DAMP signaling might drive an immune response even against innocuous antigens or aggravate a mild GN (34).

As demonstrated elegantly by Heymann et al. (18), neoantigen can be released from podocytes into the urine, where they are picked up by medullary DCs, which then migrate to the regional lymph nodes. There, with the help of $\mathrm{CD} 4^{+} \mathrm{T}$ cells, the antigen is crosspresented to $\mathrm{CD}^{+} \mathrm{T}$ cells, causing their activation and expansion. These $\mathrm{CD} 8^{+} \mathrm{T}$ cells then migrate back to the kidney and accumulate around $\mathrm{BC}$, most likely following a gradient of chemokines generated within the injured glomeruli (18). Due to cytokines released by injured glomerular cells, activated $\mathrm{CD}^{+}$cells proliferate and further attract and activate macrophages. This also results in the local proliferation of parietal cells of $\mathrm{BC}$ and the formation of cellular crescents. As long as $\mathrm{BC}$ remains intact, $\mathrm{CD}^{+} \mathrm{T}$ cells and macrophages remain outside the capsule. At this stage, the periglomerular infiltrate and the crescent formation are potentially reversible by immune-suppressive therapy. If, however, the activated parietal cells together with the pericapsular $\mathrm{CD} 8^{+} \mathrm{T}$ cells and macrophages create breaches in BC, e.g., through release of collagenases and proteases, macrophages and $\mathrm{CD} 8^{+} \mathrm{T}$ cells gain access to the glomerular space, where the $\mathrm{CD} 8^{+} \mathrm{T}$ cells now attack and destroy their target podocytes. This $\mathrm{CD}^{+} \mathrm{T}$ cell and macrophage cell-mediated, secondary glomerular injury results in an amplification loop of RPGN, independent of the initial antigen-antibody-mediated process, with destruction of glomeruli, spreading of the inflammation to the tubulointerstitium, and progressive kidney failure. At this point the usual immune-suppressive therapy has little effect.

In view of the strong association among breaches in $\mathrm{BC}$, the influx of $\mathrm{CD}^{+} \mathrm{T}$ cells and macrophages into the glomerular space, and the concomitant destruction of podocytes, the mechanisms responsible for creating the breaches in $\mathrm{BC}$ and the identification of potential, specific $\mathrm{T}$ cells cytotoxic for podocytes might prove worthy of future research. In addition, our studies also define CD8 ${ }^{+}$ T cells as potential therapeutic targets, especially as a role for $\mathrm{CD}^{+}$ $\mathrm{T}$ cells in human autoimmune kidney diseases has been defined recently $(32,35,36)$. Furthermore, animal studies have shown beneficial effects of blocking or eliminating $\mathrm{CD}^{+} \mathrm{T}$ cells in immunemediated crescentic GN $(3,4,16,17,19,37)$. We therefore propose that future therapeutic trials for crescentic GN should target CD8 ${ }^{+}$ $\mathrm{T}$ cells in order to prevent their detrimental action on podocytes and thereby the demise of glomerular and renal function.

\section{Methods}

Mouse model. Podocyte cell-specific EGFP-expressing mice (pod-EGFP) were generated by crossing IRG Cre-reporter mice with podocin- 
Cre transgenic mice (IRG;pod-Cre; all mice in fully backcrossed C57BL/6J strain), as described previously (22). pod-EGFP mice were then crossed with B10.D2 mice that harbor the H2- $\mathrm{K}^{\mathrm{d}}$ allele (The Jackson Laboratory). For EGFP- WT mouse experiments, mice generated from WT C57BL/6J crossed with B10.D2 mice were used. All experiments were performed in $\mathrm{F} 1$ progeny that were 8 to 12 weeks of age. $\mathrm{CD}^{+} \mathrm{T}$ cells were isolated from Jedi or WT control mice (C57BL/6J; B10.D2 with the H1- $\mathrm{K}^{\mathrm{d}}$ allele) and injected intravenously through the tail vein $\left(4 \times 10^{6}\right.$ cells/mouse $)$ in conjunction with $1 \times 10^{8}$ transducing units of vesicular stomatitis virus-pseudotyped (VSV-pseudotyped) LV.EGFP, as described previously (21).

Flow cytometry analysis. Peripheral blood was collected 5 days after $\mathrm{T}$ cell injection in PBS with $2 \mathrm{mM}$ EDTA plus $0.5 \%$ BSA for T cell isolation. After red blood cell lysis, the remaining blood leukocytes were stained with anti-mouse CD8a (clone 53-6.7) PerCP cyanine 5.5, anti-mouse CD45.1 (clone A20) eFluor 450, and anti-mouse CD45.2 (clone 104) APC-eFluor 780 (all from Thermo Fisher Scientific). The gating strategy used for the flow cytometry analysis to quantify Jedi $\mathrm{CD}^{+} \mathrm{T}$ cells is shown in Supplemental Figure 2. LSR-Fortessa and LSR-II (BD Biosciences) were used to acquire the samples, and FlowJo software was used to analyze the data (FlowJo LLC).

NTS-induced nephropathy. NTS was a gift from David J. Salant (Boston University Medical School, Boston, Massachusetts, USA), and NTS or PBS vehicle control was administered intraperitoneally in experimental mice as described previously (25). Three days after injection, mice received control $\mathrm{T}$ cells or Jedi $\mathrm{T}$ cells by tail vein as described (21). Eight days later, all mice were euthanized and kidneys were harvested.

Kidney function assessment. Urine albumin was measured using a commercial ELISA kit according to the manufacturer's protocol (Bethyl Laboratory). Urine creatinine levels were quantified using a QuantiChrom Creatinine Assay Kit (DICT-500, Bioassay Systems). Urine albumin excretion was expressed as albumin-to-creatinine ratio. Serum blood urea content was measured using a commercially available kit (BioAssay Systems).

Mouse kidney histology. Kidney samples were fixed in 10\% formalin, embedded in paraffin, and sectioned to $4 \mu \mathrm{m}$ thickness. PAS- and H\&E-stained kidney sections were used for kidney histology. Histological scoring was performed in a blinded manner by the renal pathologist.

Immunohistochemistry on human renal biopsies. The sample collection of the Columbia University Renal Pathology Laboratory was searched for representative renal biopsy specimens with anti-GBM nephritis $(n=7)$, ANCA-associated GN $(n=7)$, IgA nephropathy $(n=6)$, acute postinfectious $\mathrm{GN}(n=5)$, and primary membranous glomerulopathy $(n=7)$. Deidentified, $2 \mu \mathrm{m}$-thick formalin-fixed, paraffin-embedded sections were stained by immunohistochemistry with mouse monoclonal antibody to CD8 (Leica clone 4B11; catalogue PA0183) using the Leica Bond Polymer Refine Detection (Leica Biosystems; catalog DS9800). In brief, following EDTA-based antigen retrieval (pH 9), sections were incubated with $\mathrm{H}_{2} \mathrm{O}_{2}$ to quench endogenous peroxidase activity, followed by primary mouse antibody, secondary rabbit anti-mouse IgG, and polymer anti-rabbit poly-HRP-IgG, followed by chromogen $3,3^{\prime}$-diaminobenzidine tetrahydrochloride hydrate in less than $0.1 \%$ $\mathrm{H}_{2} \mathrm{O}_{2}$. Sections were then washed in PBS and counterstained lightly with PAS (to visualize renal basement membranes) and hematoxylin (to visualize nuclei). The number of total glomeruli, number of glomeruli with crescents, and number of crescents with any combination of ruptured $\mathrm{BC}$ and/or infiltrating CD8 cells were quantified for each biopsy.
Immunofluorescence staining. Mouse spleen and kidney tissues were harvested following the transcardial perfusion with $4 \%$ paraformaldehyde (PFA) in PBS, postfixed for 2 hours in $4 \%$ PFA, equilibrated in $30 \%$ sucrose overnight, and frozen in OCT (Thermo Fisher Scientific) prior to sectioning. Frozen sections of $4 \mu \mathrm{m}$ were blocked with $2 \%$ horse serum and $2 \%$ BSA in PBS and incubated overnight at $4{ }^{\circ} \mathrm{C}$ with the following primary antibodies: anti-MHC-I (catalog ab15681, Abcam), anti-mouse CD8a (catalog 100703, BioLegend), anti-mouse CD45.1 (clone A20) (catalog 110702, BioLegend), anti-CD68 (catalog ab53444, Abcam), and anti-Ki-67 (catalog 9129, Cell Signaling Technology). Secondary antibodies conjugated with fluorochromes were obtained from Jackson ImmunoResearch Labs. DAPI was used as the nuclear counterstain. Immunostained kidney sections were mounted with ProLong Gold Antifade Reagent with DAPI (Life Technologies).

TUNEL assay. The DeadEnd Colometric TUNEL System (Promega) was used to detect apoptotic cells on frozen kidney sections following the manufacturer's instructions. Cy5-conjugated streptavidin (Promega) was used to detect the apoptotic cells, and sections were then mounted with ProLong Gold Antifade Reagent with DAPI (Life Technologies).

Microscopy and image analysis. Immunofluorescence images were obtained with a Zeiss LSM microscope (Carl Zeiss Microscopy LLC) and analyzed with ZEN (Zeiss) and Image (NIH, 1997-2016) software. 3D deconvolution microscopy images were acquired using the Zeiss Axioimager Z2M microscope with ApoTome attachment. Z-stacked images were obtained and deconvolved using ImageJ software.

Fluorescence intensity and morphometric measurements of EGFP. The quantification of immunostaining and morphometric analysis for the podocyte $\mathrm{EGFP}^{+}$area was done as previously described (22). Briefly, a fixed exposure time for each channel was set based on the most optimal fluorescent signal in the glomerulus prior to image acquisition. Using the ImageJ software, intensity values were calculated by dividing the sum of all intensity values for all pixels in the selected glomerular region (integrated) by the area of the region with pixel intensities within the threshold region. All glomeruli visualized were included in the analysis.

Statistics. Data are expressed as mean \pm SD. ANOVA, followed by Bonferroni's correction, was used to analyze differences between more than 2 groups, and unpaired 2-tailed $t$ test was used when 2 groups were present. GraphPad Prism 7 software was used for statistical analyses. $P<0.05$ was considered statistically significant.

Study approval. All animal procedures were performed according to protocols approved by Institutional Animal Care and Use Committee at Icahn School of Medicine at Mount Sinai. Human archival biopsy tissues were used in accordance with Columbia University IRB no. AAAO2107.

\section{Author contributions}

$\mathrm{AC}$ designed and conducted experiments, acquired and analyzed data, and wrote the manuscript. VDD acquired and analyzed data and wrote the manuscript. CW, KL, TJG, JCH, DS, and JF designed experiments, analyzed data, and wrote the manuscript. JA designed and conducted experiments, provided reagents, and wrote the manuscript.

\section{Acknowledgments}

AC is supported by the Fujian Medical Technology Innovation Fund from China (2014-CXB-41). KL is supported by NIH 
1R01DK117913. TJG is supported by the Fujian Medical Technology Innovation Fund from China (2017-CXB-16). JCH is supported by R01DK078897. JA is supported by a Juvenile Diabetes Research Foundation postdoctoral fellowship (JDRF-3-2013-92) and the Robin Chemers Neustein award.

Address correspondence to: Detlef Schlondorff, Icahn School of Medicine at Mount Sinai, Department of Medicine, Divi- sion of Nephrology, One Gustave L. Levy Place, Box 1243, New York, New York 10029, USA. Phone: 212.241.3568; Email: detlef. schlondorff@mssm.edu.

JA's present address is: Department of Cancer Immunology \& Virology, Dana-Farber Cancer Institute and Department of Microbiology and Immunology, Harvard Medical School, Boston, Massachusetts, USA.
1. Jennette JC, Thomas DB. Crescentic glomerulonephritis. Nephrol Dial Transplant. 2001; 16(Suppl 6):80-82.

2. Assady S, Wanner N, Skorecki KL, Huber TB. New insights into podocyte biology in glomerular health and disease. J Am Soc Nephrol. 2017;28(6):1707-1715.

3. Tipping PG, Holdsworth SR. T cells in crescentic glomerulonephritis. J Am Soc Nephrol. 2006;17(5):1253-1263.

4. Suárez-Fueyo A, Bradley SJ, Klatzmann D, Tsokos GC. T cells and autoimmune kidney disease. Nat Rev Nephrol. 2017;13(6):329-343.

5. Kurts C, Panzer U, Anders HJ, Rees AJ. The immune system and kidney disease: basic concepts and clinical implications. Nat Rev Immunol. 2013;13(10):738-753.

6. Nikolic-Paterson DJ, Atkins RC. The role of macrophages in glomerulonephritis. Nephrol Dial Transplant. 2001;16 Suppl 5:3-7.

7. Xiao H, Hu P, Falk RJ, Jennette JC. Overview of the pathogenesis of ANCA-associated vasculitis. Kidney Dis (Basel). 2016;1(4):205-215.

8. Bolton WK, Innes DJ, Sturgill BC, Kaiser DL. $\mathrm{T}$-cells and macrophages in rapidly progressive glomerulonephritis: clinicopathologic correlations. Kidney Int. 1987;32(6):869-876.

9. Cunningham MA, Huang XR, Dowling JP, Tipping PG, Holdsworth SR. Prominence of cell-mediated immunity effectors in "pauciimmune" glomerulonephritis. J Am Soc Nephrol. 1999;10(3):499-506.

10. Rastaldi MP, Ferrario F, Tunesi S, Yang L, D'Amico G. Intraglomerular and interstitial leukocyte infiltration, adhesion molecules, and interleukin-1 alpha expression in 15 cases of antineutrophil cytoplasmic autoantibody-associated renal vasculitis. Am J Kidney Dis. 1996;27(1):48-57.

11. Sakatsume M, et al. Human glomerulonephritis accompanied by active cellular infiltrates shows effector T cells in urine. J Am Soc Nephrol. 2001;12(12):2636-2644.

12. Nolasco FE, Cameron JS, Hartley B, Coelho A, Hildreth G, Reuben R. Intraglomerular T cells and monocytes in nephritis: study with monoclonal antibodies. Kidney Int. 1987;31(5):1160-1166.

13. Hu SY, et al. T cell infiltration is associated with kidney injury in patients with anti-glomerular basement membrane disease. Sci China Life Sci. 2016;59(12):1282-1289.

14. Weidner S, Carl M, Riess R, Rupprecht HD. Histologic analysis of renal leukocyte infiltration in antineutrophil cytoplasmic antibody-associated vasculitis: importance of monocyte and neutrophil infiltration in tissue damage. Arthritis Rheum. 2004;50(11):3651-3657.

15. Hooke DH, Gee DC, Atkins RC. Leukocyte analysis using monoclonal antibodies in human glomerulonephritis. Kidney Int. 1987;31(4):964-972.

16. Penny MJ, Boyd RA, Hall BM. Permanent CD8(+) T cell depletion prevents proteinuria in active Heymann nephritis. J Exp Med. 1998;188(10):1775-1784.

17. Reynolds J, Norgan VA, Bhambra U, Smith J, Cook HT, Pusey CD. Anti-CD8 monoclonal antibody therapy is effective in the prevention and treatment of experimental autoimmune glomerulonephritis. J Am Soc Nephrol. 2002;13(2):359-369.

18. Heymann F, et al. Kidney dendritic cell activation is required for progression of renal disease in a mouse model of glomerular injury. J Clin Invest. 2009;119(5):1286-1297.

19. Chang J, et al. $\mathrm{CD} 8^{+} \mathrm{T}$ cells effect glomerular injury in experimental anti-myeloperoxidase GN. JAm Soc Nephrol. 2017;28(1):47-55.

20. Lan HY, Nikolic-Paterson DJ, Atkins RC. Involvement of activated periglomerular leukocytes in the rupture of Bowman's capsule and glomerular crescent progression in experimental glomerulonephritis. Lab Invest. 1992;67(6):743-751.

21. Agudo J, et al. GFP-specific CD8 T cells enable targeted cell depletion and visualization of T-cell interactions. Nat Biotechnol. 2015;33(12):1287-1292.

22. Fu J, et al. Comparison of glomerular and podocyte mRNA profiles in streptozotocin-induced diabetes. J Am Soc Nephrol. 2016;27(4):1006-1014.

23. Coers W, et al. Podocyte expression of MHC class I and II and intercellular adhesion molecule-1 (ICAM-1) in experimental pauci-immune crescentic glomerulonephritis. Clin Exp Immunol. 1994;98(2):279-286.

24. Mendrick DL, Kelly DM, Rennke HG. Antigen processing and presentation by glomerular visceral epithelium in vitro. Kidney Int. 1991;39(1):71-78.
25. Casalena G, et al. Mpv17 in mitochondria protects podocytes against mitochondrial dysfunction and apoptosis in vivo and in vitro. Am J Physiol Renal Physiol. 2014;306(11):F1372-F1380.

26. Salant DJ, Cybulsky AV. Experimental glomerulonephritis. Meth Enzymol. 1988;162:421-461.

27. Segerer S, et al. Compartment specific expression of dendritic cell markers in human glomerulonephritis. Kidney Int. 2008;74(1):37-46.

28. Ooi JD, et al. The immunodominant myeloperoxidase T-cell epitope induces local cell-mediated injury in antimyeloperoxidase glomerulonephritis. Proc Natl Acad Sci U S A. 2012;109(39):E2615-E2624.

29. Mbassa G, Elger M, Kriz W. The ultrastructural organization of the basement membrane of Bowman's capsule in the rat renal corpuscle. Cell Tissue Res. 1988;253(1):151-163.

30. O'Sullivan KM, et al. Renal participation of myeloperoxidase in antineutrophil cytoplasmic antibody (ANCA)-associated glomerulonephritis. Kidney Int. 2015;88(5):1030-1046.

31. Watanabe T, Kawachi H, Ikezumi Y, Yanagihara T, Oda Y, Shimizu F. Glomerular CD8 $8^{+}$cells predict progression of childhood IgA nephropathy. Pediatr Nephrol. 2001;16(7):561-567.

32. Couzi L, et al. Predominance of CD8 ${ }^{+} \mathrm{T}$ lymphocytes among periglomerular infiltrating cells and link to the prognosis of class III and class IV lupus nephritis. Arthritis Rheum. 2007;56(7):2362-2370.

33. Galluzzi L, Buqué A, Kepp O, Zitvogel L, Kroemer G. Immunogenic cell death in cancer and infectious disease. Nat Rev Immunol. 2017;17(2):97-111.

34. Anders HJ, Banas B, Schlöndorff D. Signaling danger: toll-like receptors and their potential roles in kidney disease. J Am Soc Nephrol. 2004;15(4):854-867.

35. McKinney EF, et al. A CD $8^{+} \mathrm{T}$ cell transcription signature predicts prognosis in autoimmune disease. Nat Med. 2010;16(5):586-591.

36. McKinney EF, Lee JC, Jayne DR, Lyons PA, Smith KG. T-cell exhaustion, co-stimulation and clinical outcome in autoimmunity and infection. Nature. 2015;523(7562):612-616.

37. Kawasaki K, Yaoita E, Yamamoto T, Kihara I. Depletion of CD8 positive cells in nephrotoxic serum nephritis of WKY rats. Kidney Int . 1992;41(6):1517-1526. 